\title{
La heterodoxia en la poesía visual española del siglo XXI
}

\section{Heterodoxy on Spanish Visual Poetry of XXI Century}

\author{
Marina Bianchi \\ UNIVERSITÀ DEGLI STUDI DI BERGAMO · marina.bianchi@unibg.it
}

Profesora en la Universidad de Bergamo desde 2002 y Doctora en Iberística por la Universidad de Bologna, forma parte del Colegio Docentes del Doctorado en Política, Cultura y Desarrollo del Departamento de Ciencias Políticas y Sociales de la Universidad de Calabria, es miembro del Comité de Redacción de la revista Quaderni Ibero-Americani como editora del suplemento virtual Duende, y es codirectora, con Mario F. Benvenuto, de la colección editorial Versus. Poesia spagnola e ispanoamericana contemporanea, de Iride grupo Rubbettino. Sus publicaciones incluyen artículos en revistas internacionales, capítulos de libros, ediciones de actas de congresos, la monografía M. B., Vicente Núñez: parole come armi, Barcellona Pozzo di Gotto (ME), Edizioni Smasher, 2011, y seis ediciones críticas

Resumen: Toda vanguardia esconde un malestar y una rebeldía contra la realidad que aflige al individuo y que se vuelve objeto de crítica en las obras. En este sentido, tras aclarar a qué nos referimos cuando hablamos de poesía visual, analizaremos algunas obras que han aparecido por primera vez en 2014, interpretándolas como reacción contra la pérdida de valores de la sociedad postmoderna. La finalidad será demostrar que la poesía visual española del siglo XXI no ha renunciado a su heterodoxia, puesto que elige justamente este universo donde todo es rápido, fluido, superficial, complejo e inasible para seguir denunciando desde su interior la incomunicación y la alienación a la que nos han llevado el consumismo y la cultura de masas.

Palabras clave: poesía visual, compromiso ético, cultura de masas, incomunicación, alienación
Abstract: All Vanguards implies uneasiness and rebellion against the reality that afflicts the individual and that becomes object of criticism in the works. After clarifying what we mean when we speak of visual poetry, we will analyze some works that appeared in 2014, interpreting them as a reaction against the loss of values of postmodern society. We want to demonstrate that the Spanish visual poetry of the 21st century has not given up his heterodoxy, since it just chooses this universe where everything is fast, fluid, frivolous, complex and incomprehensible to denounce from inside the incommunication and the alienation caused by consumerism and mass culture.

Key Words: visual poetry, ethical commitment, mass culture, incommunication, alienation.

DOI: $10.7203 /$ KAM.4.4240 


\section{Cuestiones previas y marco teórico}

Las vanguardias en todas sus manifestaciones, desde la histórica al postismo, al experimentalismo de los años setenta, hasta llegar a la poesía visual de nuestros días, siempre se han declarado fieles al rechazo del concepto del arte como imitación, a la finalidad estética y al deleite exento de realismo. De alguna manera, se trata de la distinción que Jorge Urrutia establece en su defensa de la poética novísima frente a los que pretenden transcribir el mundo en el verso, ya sea desde la poesía social de los años cincuenta y sesenta, o desde la poesía de la Experiencia de los años ochenta: Urrutia (1999: 135-136) distingue entre "poesía del decir" y "poesía del contar", donde la primera crea una nueva realidad y nuevas relaciones a partir de un punto de vista, sin referencialidad, buscando la esencialidad de las cosas y expresando lo interior y el modo de comprender el mundo del poeta; la segunda es un testimonio de la realidad, refiere un mundo anterior a ella y describe lo que el escritor contempla, poniendo en relación unos objetos con otros y ubicándose por completo en la dimensión mimética.

Si por un lado la poesía visual se inserta sin dudas en la primera tipología y propone actos creativos cuya finalidad es evidentemente estética, por otro no hay que olvidar que toda vanguardia esconde un malestar, un trasfondo ideológico, un sentimiento de alienación que provoca una rebeldía contra la realidad que aflige al individuo y que se vuelve objeto de crítica en las obras, aunque se enjuicie de forma sensacional y chocante. Desde luego, por mucho que se aleje del mundo que rodea al artista, la creación siempre surge a partir de su relación con él y de su toma de posición frente a él.

La noción de compromiso procede de Jean-Paul Sartre, quien en su Qu'est que c'est la litterature de 1948 afirma que revelar es cambiar y que nadie puede ignorar el mundo (Sartre, 1948: 27-30); profundizando en el mismo concepto, Roland Barthes remarca en Le degré zéro de l'écriture de 1953 que la escritura siempre es un acto de solidaridad histórica (Barthes, 1953: 24) y que la dimensión social implica una toma de posición ineludible, excepto en una escritura perfecta y neutra, necesariamente utópica, en la que el lenguaje no esté alienado (Barthes, 1953: 70-71). A su vez, Theodor Adorno, en sus Notas sobre literatura de 1962, considera el compromiso no como una elección, sino más bien como una compleja relación con la realidad de la que toda la literatura procede, incluida la que quiere huir de ella para afirmar su autonomía (Adorno, 2003: 393-413); por último, en Marxismo y literatura de 1977, Raymond Williams (1997: 233-234) insiste en que la alienación y el compromiso son complementarios.

En este sentido, intentaremos analizar aquí la poesía visual como reacción contra la pérdida de valores de la sociedad postmoderna descrita por Guy Debord, Marshall McLuhan, Jean Baudrillard, Fredric Jameson, entre otros ${ }^{1}$ : la de la cultura del espectáculo, del simulacro y del consumo, donde la vida se reduce a una serie de imágenes y priman la apariencia, la ambigüedad, el deseo reprimido, la falta de profundidad y la complejidad. La

\footnotetext{
${ }^{1}$ Concretamente, nos referimos a La société du spectacle de Guy Debord (1967), a Understanding Media: The Extensions of Man (1964) y a War and Peace in the Global Village (1968), ambos de Marshall McLuhan, a Simulacres et Simulation de Jean Baudrillard (1981), y por último a Postmodernism, or, The Cultural Logic of Late Capitalism de Fredric Jameson (1991).
} 
finalidad será demostrar que la poesía visual supera esa dimensión de la autosuficiencia postmoderna que proclama la metarrepresentación (la representación como construcción para dar cuenta de una realidad en la que ya todo se representa), en la medida en que elige justamente este universo donde todo es rápido, fluido, superficial e inasible como objeto designado para sus críticas y denuncias. Conscientes de que la poesía visual, sin voluntad de condicionar al público, en ningún momento pretende hacerse portavoz del pueblo, queremos profundizar en el sentimiento que en ella se sigue expresando y que hoy reconocemos como colectivo, o por lo menos muy difundido, desde los ámbitos más dispares.

Desde las teorizaciones de Jurij Lotman sabemos que en la interpretación de la obra de arte el receptor percibe el mismo lenguaje como mensaje, puesto que la totalidad de la estructura del texto se percibe como única, irrepetible e individual; sin embargo, la misma obra, por lo menos la de calidad, debería aspirar a volverse universal y a formar parte del lenguaje de la tradición para los escritores futuros, es decir, del código -como conjunto de unidades de significación, con sus reglas combinatorias y su estructura, que sirve para la comunicación, verbal o no- para la posteridad. Esta ambición depende en larga medida del hecho de que el arte es una forma de conocimiento (Lotman, 1978: 9-10) que supone un modelo determinado del mundo (Lotman, 1978: 69) -y añadiríamos que más de uno, puesto que al del autor se suman los puntos de vista de los destinatarios, de acuerdo con el principio de la cooperación interpretativa de Umberto Eco (cfr. 1979 y 1990)².

Según Lotman (1978: 194), además, la obra, aunque sea literaria, no consiste en una pura sucesión de signos, sino en un todo estructural, y no sigue los mismos procedimientos de significación de la lengua natural, debido a la peculiar correlación entre contenido y expresión. El alfabeto poético al que nos referimos, de gran complejidad y extrema capacidad de condensación, es un sistema de modelización secundario (Lotman, 1978: 34), ya que a partir del material de una lengua humana surge un discurso que la considera como parte de su significante para expresar el sentido del texto, pero no se confunde con ella porque no pertenece al mismo sistema semiótico. Pese a ello, el mensaje transmitido mediante el lenguaje de la creación no deja de hacer referencia al mundo real, del que se sirve, como del lenguaje, para construir sobre él. Lo mismo ocurre con la tradición: las obras precedentes influyen en el código presente y dejan huellas en el contenido. Por esta razón, para interpretar el alfabeto de la poesía visual habrá que recurrir a la tradición de las vanguardias, de las que procede asimilándolas y con las que establece inevitablemente un diálogo, de acuerdo con el dialogismo, la dimensión social del lenguaje y la polifonía de Mijaíl Bajtín (1986: 15 y 278-279), o la intertextualidad, como la denomina Julia Kristeva (1981: 66-67).

\footnotetext{
${ }^{2}$ Según la cooperación interpretativa de Umberto Eco, el lector no debería contentarse con observar y juzgar desde el papel pasivo del espectador, sino hacerse cargo de una colaboración que genere sentido -y no sólo permita comprenderlo-: el escritor le pide que coopere, con sus conocimientos enciclopédicos previos que posibilitan el correcto posicionamiento del texto en su contexto, para que entienda más allá del significado de las palabras (Eco, 1979: passim y especialmente 17, 52-55; Eco, 1990: passim). Por esta razón, Eco define el texto como: "objeto y parámetro de sus interpretaciones" (Eco, 1990: 11) (la traducción es mía).
} 
Por supuesto, estamos asumiendo como base de partida la superación postestructuralista de la autosuficiencia del lenguaje poético, y el planteamiento de la pragmática del discurso (Austin, 1962; Searle, 1969; Grice, 1975: 41-58; Sperber y Wilson, 1986), según la que el texto literario es un acto comunicativo que se inserta y se deja influenciar por un contexto determinado, cuya finalidad es la de generar representaciones del mundo en la mente del interlocutor: en otras palabras, aunque incorpore la perspectiva personal del autor, la poesía visual será para nosotros un producto cultural de un lugar y un momento determinado.

\section{La poesía visual}

\subsection{Para una definición de la poesía visual}

Juan Antonio Ramírez (1997: 190) define la poesía visual como: "un sistema connotado complejo cuyo plano de expresión está constituido por una fusión de la significación del texto y de la significación de la imagen”. En la misma línea y parafraseando lo afirmado por Xavier Canals (1999: 88), Blanca Millán Domínguez (2014: 113-114) remarca que se trata de artistas que aspiran a "la creación de un nuevo género, en función de la especificidad de la integración de lo icónico y lo discursivo". Desde una perspectiva más amplia, Gustavo Vega (2005: s. p.) apunta que la expresión se refiere a: "ciertas formas de creación poética basadas en recursos visuales", que incluyen productos creativos muy variados: "desde los que son estrictamente lingüístico-estructurales a formas de creación plástica cuyos elementos funcionan como semantemas o referencias metafórico-poéticas". Los citados, entre muchos otros, hacen hincapié en los dos aspectos indivisibles de esta forma artística: por un lado queda patente el protagonismo imprescindible de lo visual; por otro, para que encajen en el nuevo género textual, las obras tienen que guardar alguna relación tanto con la escritura y el lenguaje -o por lo menos con elementos que funcionen como analogía de ellos-, como con la poesía y sus procedimientos metafóricos (Vega, 2005: s. p.).

Gustavo Vega (2005: s. p.) distingue cinco modalidades de la poesía visual: los poemas visuales texto-discursivos, que son formas poéticas textuales creadas para ser vistas, como el caligrama, las palabras en libertad o los poemas acrósticos; los poemas textovisuales no discursivos, donde el texto queda reducido a muy pocas palabras o se pierde del todo, permaneciendo tan sólo en la presencia de la letra como cuerpo, incluyendo aquí las poéticas concretistas, espacialistas, grafistas, tipoletristas y el Letrismo; las formas mixtas o poemas texto-icónicos en los que conviven y se interrelacionan el texto y el elemento gráfico; las metáforas icónicas, a veces muy fronterizas y lejanas a la poesía, en las que las palabras se sustituyen por imágenes plásticas que dejan surgir la metáfora a través de su acumulación; los poemas tridimensionales, como el poema-objeto, el poema-libro, el poema-escultura o el poema-instalación; las poéticas dinámicas, que tienen que ver con la performance y otros elementos procedentes del mundo teatral y de la actuación; las poéticas multimedia, que aprovechan las nuevas tecnologías, como la poesía infográfica o la poesía virtual. 
En nuestra opinión, sólo las primeras tres, en las que nos centraremos, pertenecen a la poesía visual en un sentido propio, quedando las demás en zonas muy fronterizas, en línea tanto con la integración vanguardista de las artes y de éstas con la vida, como con su voluntad de impactar sobre el público, pero muy alejadas de la palabra y, por ende, de la poesía como género literario. Otra cuestión tiene que ver con los ideogramas u otros elementos sígnicos que reconocemos como convencionales o familiares, como las señales de tráfico, que Gustavo Vega (2005: s. p.) considera como elementos textuales, aunque no como escritura; nosotros propenderíamos más bien por incluirlos en las metáforas icónicas, puesto que, tal y como lo plantea Juan Carlos Fernández Serrato (2014: 143), los lenguajes visuales incluyen los signos icónicos y las imágenes no figurativas, mientras que los verbales se basan "en el uso de la palabra y la letra individualizada".

Finalmente, creemos que habría que aclarar a qué nos referimos al hablar de poesía; sin entrar en cuestiones retóricas y en los géneros discursivos propios de la literatura, conceptos que la poesía visual quiere superar, el diccionario on-line de la Real Academia Española proporciona las siguientes definiciones:

1. f. Manifestación de la belleza o del sentimiento estético por medio de la palabra, en verso o en prosa.

2. f. Cada uno de los géneros en que se dividen las obras literarias. Poesía épica, lírica, dramática.

3. f. Por antonom. poesía lírica.

4. f. Poema, composición en verso.

5. f. Poema lírico en verso.

6. f. Idealidad, lirismo, cualidad que suscita un sentimiento hondo de belleza, manifiesta o no por medio del lenguaje.

7. f. Arte de componer obras poéticas en verso o en prosa.

Excepto la sexta, las demás remiten de manera evidente a la escritura, razón por la que, aunque puede que a contracorriente, consideramos que la poesía visual debería implicar siempre una relación con ella, por lo menos desde el juego formal, sin la que sería más adecuado calificarla de creación plástica.

\subsection{El origen de la poesía visual}

El desplazamiento de la base del poema desde el verso hacia la disposición visual de la palabra sobre la página tiene orígenes muy antiguos (cfr. Cózar, 1991), aunque el siglo XX lo ha revitalizado de forma revolucionaria y con implicaciones muy distintas. En palabras de Rafael de Cózar:

Puede decirse, en este sentido, que hay una tradición literaria formalista y artificiosa tan antigua y continuada como la de la poesía discursiva, aunque a menudo denostada por la teoría literaria. Es lo que se llamó poesía artificiosa, extravagancias literarias, esfuerzos de ingenio, o rarezas literarias, todo ello antes de iniciarse la vanguardia (Cózar, 2013: 7).

Según la síntesis que el crítico proporciona (Cózar, 2013: 10-13 y 2014: 5-12), las primeras formas de lo que hoy denominaríamos poesía visual se remontan al technopaegnia 
griego de Alejandría, en la época de la decadencia económica de la gran cultura helenística, y a los carmina figurata latinos de finales del siglo III d.C. y del siglo IV d.C., etapa del declive de la cultura romana; a esta herencia se añade la influencia procedente de las culturas árabe y hebrea (Cózar, 2014: 14). El interés por estos artificios y por la dimensión plástica en la escritura vuelve a aparecer cada vez que hay una recuperación del clasicismo: en el renacimiento carolingio del siglo IX, en el "trovar clus" de la poesía trovadoresca del final de la Edad Media, en los siglos XVI y XVII con el Renacimiento y el Barroco. Por el contrario, el Neoclasicismo del siglo XVIII rechaza estas formas de literatura, que tampoco logran afirmarse durante el Romanticismo, aunque, como remarca Cózar (2012: 8), no podemos olvidar la defensa de la libertad formal llevada a cabo desde el Romanticismo, el Simbolismo, el Parnasianismo y el Modernismo. Tras la mímesis radical del Realismo, a finales del siglo XIX, las vanguardias contestan la postura que pretende ilustrar lo que ocurre en el mundo con una finalidad evidentemente pedagógica, alejándose de la realidad para crear otra distinta en la obra de arte. Como aclara Cózar:

la conclusión parece evidente: el arte puro, el esteticismo por sí mismo y el artificio se producen en las etapas de crisis, de decadencia de una cultura, de un sistema, mientras en los momentos en que un nuevo sistema se está asentando la literatura y el arte se vuelcan en apoyarlo e ilustrarlo. [...]

Cuando el sistema está ya asentado y empieza a mostrar sus fisuras (la guerra mundial, el crack económico de 1929 y la crisis de la industrialización) el arte reacciona encerrándose en sí mismo y con abierta oposición al sistema: el movimiento Dadaísta, que no puede entenderse fuera del contexto de la primera guerra mundial, bastaría como ejemplo de rechazo de todo el arte anterior y de sus museos, porque son, en definitiva, parte del sistema (Cózar, 2013: 13).

Por otra parte, la superación de las barreras entre las artes es la consecuencia de la hegemonía de la forma:

Una vez perdido el papel de las artes como vehículos de una información referencial, de un contenido procedente de la realidad, no es ilógico que se llegue a una concepción de la pintura como materia plástica desarrollada en el plano a través de líneas, manchas, colores; a la música como encadenamiento de sonidos, armónicos o no; a la escultura como trabajo en volumen sobre la materia; a la danza como movimiento y a la literatura como conjunción de signos gráficos o de sonidos, sin referencia a un sentido.

Y en esa situación cabe entender que pronto se desarrolle, por ejemplo, la escultopintura, o la poesía visual. Es esa antigua aspiración de un lenguaje total: esas "palabras que fuesen a un tiempo suspiros y risas, colores y notas" de que nos habla Bécquer, o ese lenguaje al que se refiere Rimbaud "del alma para el alma, resumiendo todo, perfumes, sonidos, colores..." (Cózar, 2014: 21-22).

Tras la época de la vanguardia histórica, que se asienta en España gracias a la Generación del 27, la Guerra Civil y la dictadura suponen el acercamiento a la denuncia y a la escritura testimonial: con excepción del Postismo -que juega con el lenguaje, mezclando la poesía, las artes plásticas y la música, dándole preponderancia a la dimensión sonora-, 
para asistir a una nueva vuelta al esteticismo habrá que esperar hasta la poesía experimental de los setenta.

Sin embargo, los referentes directos de los poetas visuales parecen ser otros, entre los que destacan Stéphane Mallarmé con su poema tipográficamente atípico "Un golpe de dados" de 1897; el uso plástico de la palabra en los Calligrammes (1912-1917) de Guillaume Apollinaire; las Palabras en libertad y las "tavole parolibere" del Futurismo italiano; la tipografía revolucionaria de los movimientos de vanguardia rusos; el collage dadaísta; la reducción del texto verbal a simples letras del Letrismo de los años cuarenta; el lenguaje entendido como acto fonético y visual, más allá del nivel semántico, del Concretismo brasileño de los cincuenta (cfr. Millán Domínguez, 2014: 114-115).

Ya desde la segunda mitad de los años sesenta, época en que España sale del aislamiento y asiste a un rápido crecimiento económico que conlleva la difusión de los medios de comunicación de masas, empiezan a surgir distintos grupos y personalidades todos desde la experimentación vanguardista pero sin juntar sus esfuerzos-, que se encaminan hacia el activismo crítico, denunciando los efectos del capitalismo y reafirmando la libertad personal (Orihuela, 2014: 62-65). Blanca Millán Domínguez (2014: 113) indica $1964^{3}$ como fecha de nacimiento de la poesía visual como manifestación artística. Esta actitud se va reforzando con el final de la dictadura franquista, momento en que la publicidad y las leyes del mercado se imponen de forma aún más evidente: en 1975, se publica la antología La escritura en libertad, en edición de Jesús García Sánchez y Fernando Millán (1975), primer volumen fácilmente accesible al público no especializado, que recoge a autores de diecinueve países, incluyendo España.

Los años ochenta suponen la consolidación de la poesía visual como género, la incorporación de una nueva generación de creadores (Millán Domínguez, 2014: 122) y la gran difusión de la nueva forma artística hacia el final de la década; al mismo tiempo, la difusión del mail arty del fanzine proporciona medios en los que la poesía visual encuentra soportes nuevos que facilitan el intercambio creativo por vías no convencionales (Orihuela, 2014: 73). El logro de los noventa, que supone una nueva expansión, tiene que ver con lo virtual: con internet para la difusión y con la tecnología que facilita la elaboración gráfica. Finalmente, a principios del siglo XXI, estas nuevas formas artísticas se convierten en materia de estudio en los circuitos académicos y alcanzan el merecido lugar en la historia del arte y de la literatura (Millán Domínguez, 2014: 71-72).

\section{La heterodoxia en la poesía visual}

\subsection{Contra la sociedad en la que vivimos}

En el número de la revista Tintas dedicado a la poesía visual y apropiadamente titulado Experimental, Antonio Orihuela firma el artículo "La poesía experimental en España (1964-2004)", que se abre con una elocuente descripción de la influencia del capitalismo sobre el arte:

\footnotetext{
${ }^{3}$ La fecha es la de la publicación del ya citado libro de McLuhan, Understanding Media: The Extensions of Man (1964), sobre la difusión de los medios de comunicación de masas.
} 
Si hasta el siglo XIX no se supo qué era la explotación, desde los años sesenta del siglo XX nos hemos olvidado de ella. Viviendo sumidos cuando no directamente abstraídos en ese universo de objetos e imágenes que han sustituido a la verdadera vida nos hemos entregado al capital que, travestido de imágenes es, todavía hoy, el rostro que, a pesar de estar en todas partes y de organizar en torno a sí todos los medios de vida y todas las ilusiones, no puede verse.

Bastó que en occidente, a partir de los años cincuenta, se consiguiera alcanzar el grado de acumulación suficiente como para que el capital se convirtiera definitivamente en imagen, para que comenzara entonces la sociedad del espectáculo, el tiempo en el que los individuos serían vividos por las imágenes; la época en la que al trabajador se le exigirá una colaboración adicional para ser explotado también como consumidor (ser consumidor terminará convirtiéndose en la exigencia para que el trabajo exista), y que, en tanto consumidor, olvide el origen de su explotación y aprenda a vivirla como un fenómeno desgajado de sí a cambio de poder sentirse partícipe de la cultura y la sociedad burguesa que lo disolvió como clase y transformó el proletariado en la actual sociedad de masas donde los individuos desclasados, aislados y amedrantados, son incapaces de pensar otras formas de relacionarse y otra vida que no sea la que se les ofrece mediada por la propaganda o el espectáculo. Las mejoras en su nivel de vida lejos de traer el socialismo desarrollaron una sociedad consumista y represiva (Orihuela, 2014: 57-58).

Orihuela explica luego que, influenciando la mentalidad de todos, la sociedad industrial empieza a aparecer también en el arte, como "relación entre cultura y economía" (Orihuela, 2014: 58), es decir, entre los que definen la realidad y los que controlan la producción, de tal manera que el consumismo lleva también a formas de creación para las masas: los objetos y las imágenes de la vida diaria, difundidos mediante la publicidad, conquistan su lugar en las artes. Por otra parte, los nuevos ritmos vitales se reflejan en las formas de percepción, que, por ende, piden dinamismo e instantaneidad, lo que queda patente desde la velocidad futurista hasta nuestros días: todo es rápido, fugaz y precario. La imágenes se ajustan a esta perspectiva por su inmediatez y el mercado elige los lenguajes visuales para incrementar la demanda a través de la publicidad, que anula el mundo real para sustituirlo con el de la cultura de masas: "Catálogos, carteles, vallas publicitarias, señales de tráfico, postales, pegatinas, calendarios, periódicos, revistas, libros, tejidos, etc. serán sus encarnaciones ya dispuestas para dar forma y sentido a nuestras vidas" (Orihuela, 2014: 59).

Frente a esta situación, el artista tiene que elegir entre rendirse al consumismo que ha convertido al hombre en una máquina o desertar. Pese a sus diferencias, todas las vanguardias que se han sucedido desde comienzos del siglo pasado han preferido la segunda opción, rebelándose a la lógica del mercado desde formalizaciones icónicas que no son sino:

un lenguaje interceptado, descoyuntado, incoherente, inconsciente, descontrolado, fragmentado, mezclado y desmontado que se formalizará como poesía escénica, caligrama, collage dadaísta, poesía cubista, frottage, cadáveres 
exquisitos, fotomontaje, ready made, poligrafía, dripping, letrismo, concretismo, decollage, conceptualismo, tergiversación, distanciamiento, camuflaje, graffitis, assemblages, etc. para recomponer, con sentido crítico, un ataque a las leyes asociativas de lo lógico y lo normal (Orihuela, 2014: 60).

Llegados a este punto nos alejamos de los planteamientos de Orihuela, quien apunta que en el mismo momento en que surgían estos lenguajes sintéticos e ideográficos "también eran fagocitados por el mismo modelo productivo al que atacaban" (Orihuela, 2014: 60). Por el contrario, en nuestra opinión se trata de denunciar sus males desde dentro, apropiándose de su propio código: el de la imagen inmediata. En este sentido, es un procedimiento parecido al elegido por muchas mujeres escritora que, a finales del siglo XIX y principios del siguiente, eligieron 'escribir como un hombre', adoptando como punto de partida no sólo la lengua, sino también el mismo estereotipo difundido desde los ámbitos masculinos, para luego deconstruirlo y demostrar su falta de validez ${ }^{4}$. Asimismo, aquí estamos frente a autores que se apropian del código difundido por la cultura de masas, para modificar sus significados y la visión del mundo que propone.

En otras palabras, nos interesa hacer hincapié en la crisis que se refleja en el arte como pérdida de confianza en el lenguaje tradicional, no sólo poético, y como necesidad de encontrar formas no sometidas a las convenciones habituales, que hoy siguen expresando la disidencia y la contestación contra un sistema cultural no compartido, impuesto desde el poder del capitalismo. Queremos defender la vigencia de esta faceta de la poesía visual, en oposición a las teorías que apuntan que el nuevo género ha ido perdiendo su connotación social y su rebeldía.

\subsection{La incomunicación y la alienación en la poesía visual del siglo $X X I$}

Entre los numerosos poetas visuales que siguen trabajando en esta dirección elegimos algunas obras aparecidas en 2014, en el segundo tomo del ya citado monográfico Experimental de la revista milanesa Tintas, coordinado por Raúl Díaz Rosales (2014b) , o en el n. 9 de Duende. Suplemento virtual de Quaderni Ibero Americani (Bianchi, 2014). Pese a que se le considera el mayor representante de la poesía visual, no incluimos aquí a Joan Brossa (Barcelona 1919-1998), de la vanguardia catalana, por no cumplir el requisito de ser un artista vivo que sigue produciendo en nuestros días. Conscientes de las múltiples interpretaciones a las que estos productos artísticos se abren, intentaremos usar unas claves hermenéuticas reconocidas y asentadas entre los especialistas del género, muchas de ellas reunidas en el artículo "Poéticas tridimensionales (España 1970-1995)" de Gustavo Vega Mansilla (2014: 151-166), o procedentes de la exégesis poética tradicional.

No sólo entre los elegidos aquí, muchos poetas visuales hacen hincapié en la falta de comunicación o su alteración mediatizada, en una actitud que demuestra la pérdida de confianza en el lenguaje; el silencio se expresa mediante letras que no se juntan para formar palabras o frases, signos gráficos que pierden su función, textos tachados o borrados que denuncian la ausencia de imparcialidad y, por lo tanto, de libertad.

4 Expliqué este procedimiento en el ensayo "Los artículos 'a lo femenino' de María de la Concepción Gimeno de Flaquer" (Bianchi, 2008: 22-24). 


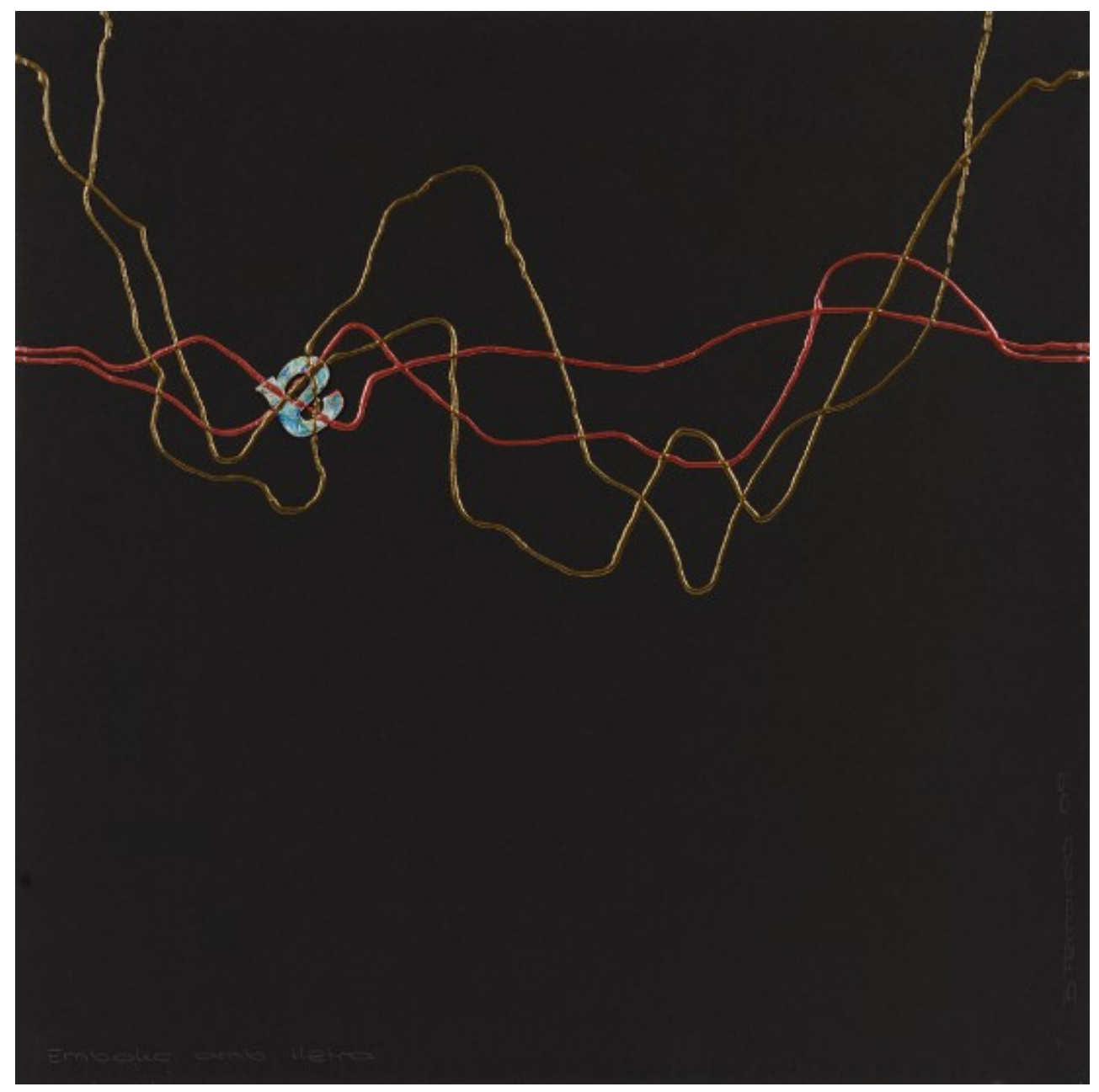

Bartolomé Ferrando, Enredo con letra

En este primer grupo, "Enredo con letra" (Bianchi, 2014: 12) de Bartolomé Ferrando (Valencia, 1951) propone una 'a' minúscula, atrapada en un enredo de alambres rojos y color oro, que sobresalen en un fondo negro, símbolo de muerte. La primera letra del abecedario, presencia constante en la poesía visual, aparece retenida al revés, lo que hace hincapié en su imposibilidad comunicativa y en la pérdida de su utilidad: siendo el elemento que origina el alfabeto y por ende el lenguaje, su detención y desfuncionalización se puede leer como falta de libertad del verbo, condicionado por la cultura de los medios de masas, o como imposibilidad de crear una nueva lengua que se escape a la hegemonía impuesta por el consumismo, en un texto que se proclama contrario a la instrumentación mediática.

En la misma línea, Julia Otxoa (San Sebastián, 1953) usa la letra 'A' mayúscula en su "Derecho a la educación" (Díaz Rosales, 2014b: 198), donde mantiene la sinécdoque de la parte, la letra, que designa el todo, el lenguaje formado por el alfabeto; de la misma manera, por significación metonímica, el idioma se vuelve metáfora del conocimiento. La 'A' en la cuchara es un correlato visual de la comida, al que el título añade la clave para la correcta interpretación: la educación es tan importante para el ser humano como lo es la alimentación. De hecho, ambas aparecen en la Declaración Universal de Derechos 
Humanos $^{5}$, donde además leemos que por lo menos la instrucción básica debe ser gratuita, y en todos sus niveles debe ser finalizada al pleno desarrollo de la personalidad y al fortalecimiento de las libertades fundamentales, favoreciendo la comprensión y la tolerancia sin discriminaciones. Se deduce fácilmente el mensaje de la obra: reclamamos el derecho a una educación abierta, ética e imparcial, que no esté finalizada a producir máquinas para el consumo, sino hombres y mujeres conscientes y libres.

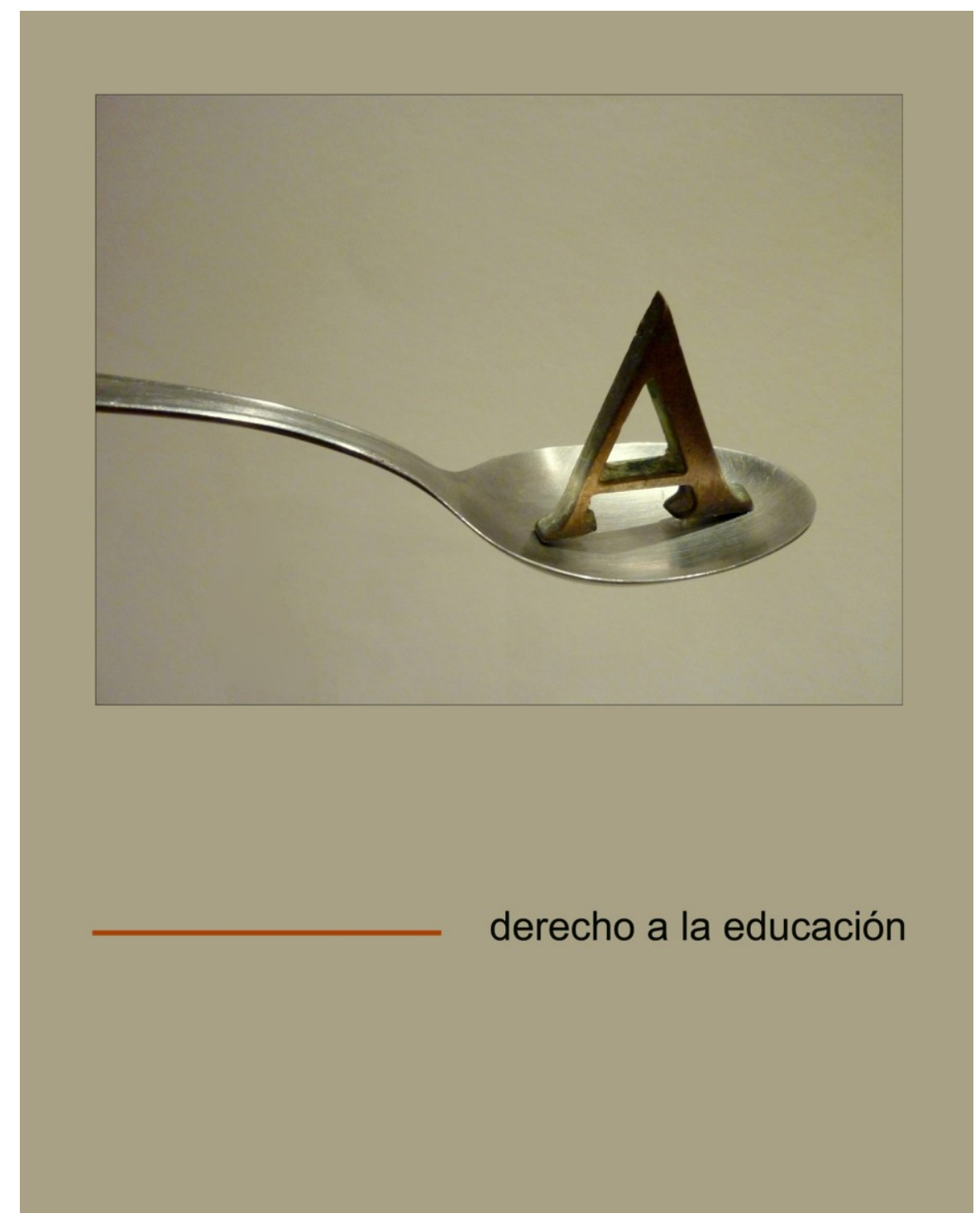

Julia Otxoa, Derecho a la educación

Por otra parte, el poema borrado es objeto de "Homenaje a Cernuda" (Díaz Rosales, 2014b: 384) de Agustín Calvo Galán (Barcelona, 1968), donde los versos de "Si el hombre pudiera decir" son de difícil lectura, debido a la elección tipográfica del carácter desenfocado, a la imagen del sevillano colocada delante del texto y a las palabras "hombre / nombre" rodeadas por el círculo blanco. La obra se podría leer como intento de superación de la poesía tradicional, pero la elección de la composición no puede ser casual. Desde

\footnotetext{
${ }^{5}$ Respectivamente, en los artículos n. 26 y n. 25 (Asamblea General de las Naciones Unidas, 1948).
} 
luego, suprimir el deseo cernudiano, el anhelo de vivir y expresar libremente su amor homosexual, dejando completamente visible sólo el íncipit -"Si el hombre pudiera decir lo que ama, / Si el hombre pudiera levantar su amor por el cielo"- junto a fragmentos entre los que sobresale "Libertad no conozco" y en los que la palabra 'libertad" aparece cuatro veces tiene un significado muy claro: el mensaje tiene que ver con la reprobación, la falta de tolerancia y los perjuicios, remarcando que hoy, como ayer o más que ayer, no somos dueños de nuestras acciones, por lo límites que la sociedad impone.

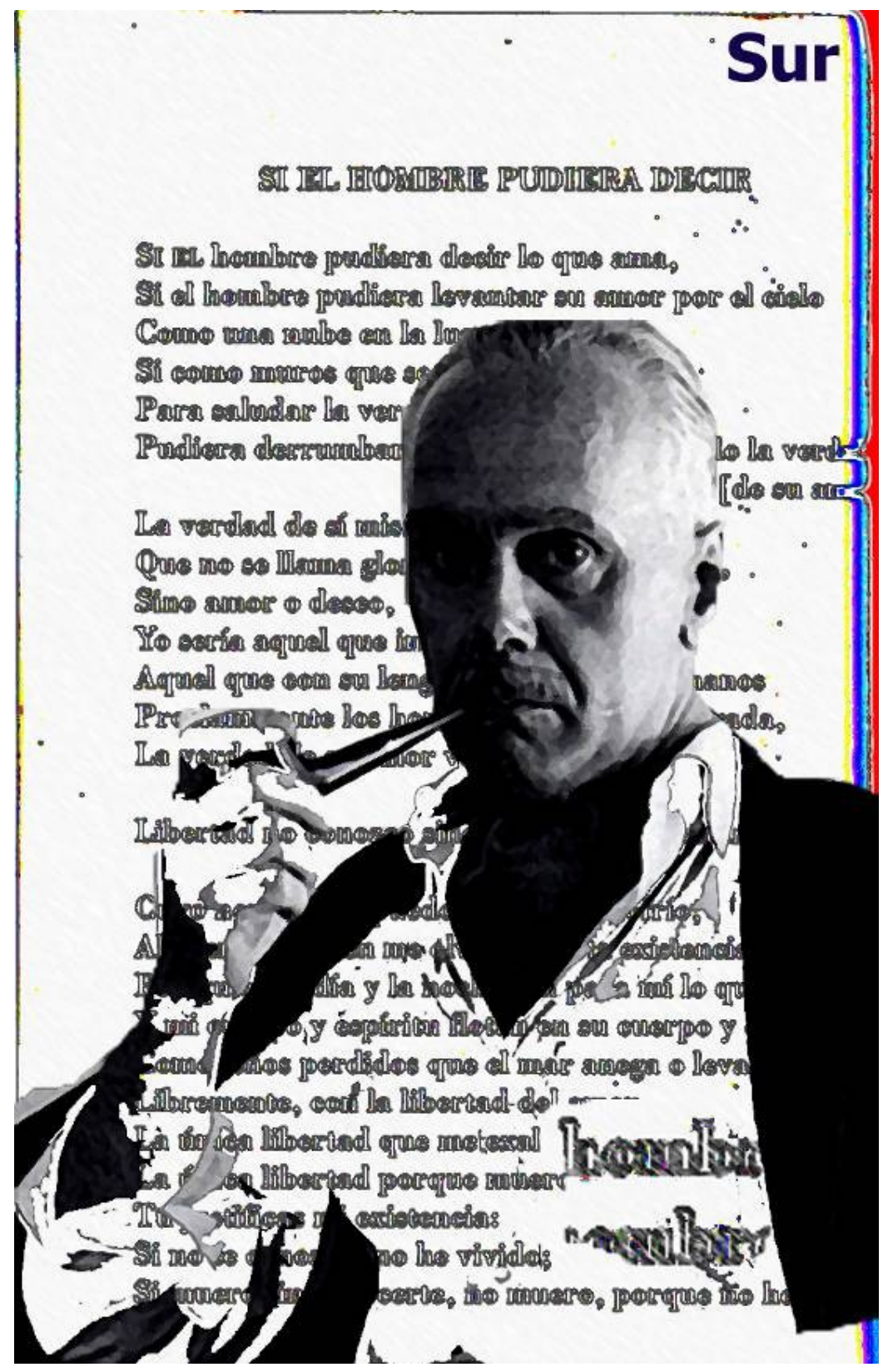

Agustín Calvo Galán, Homenaje a Cernuda 


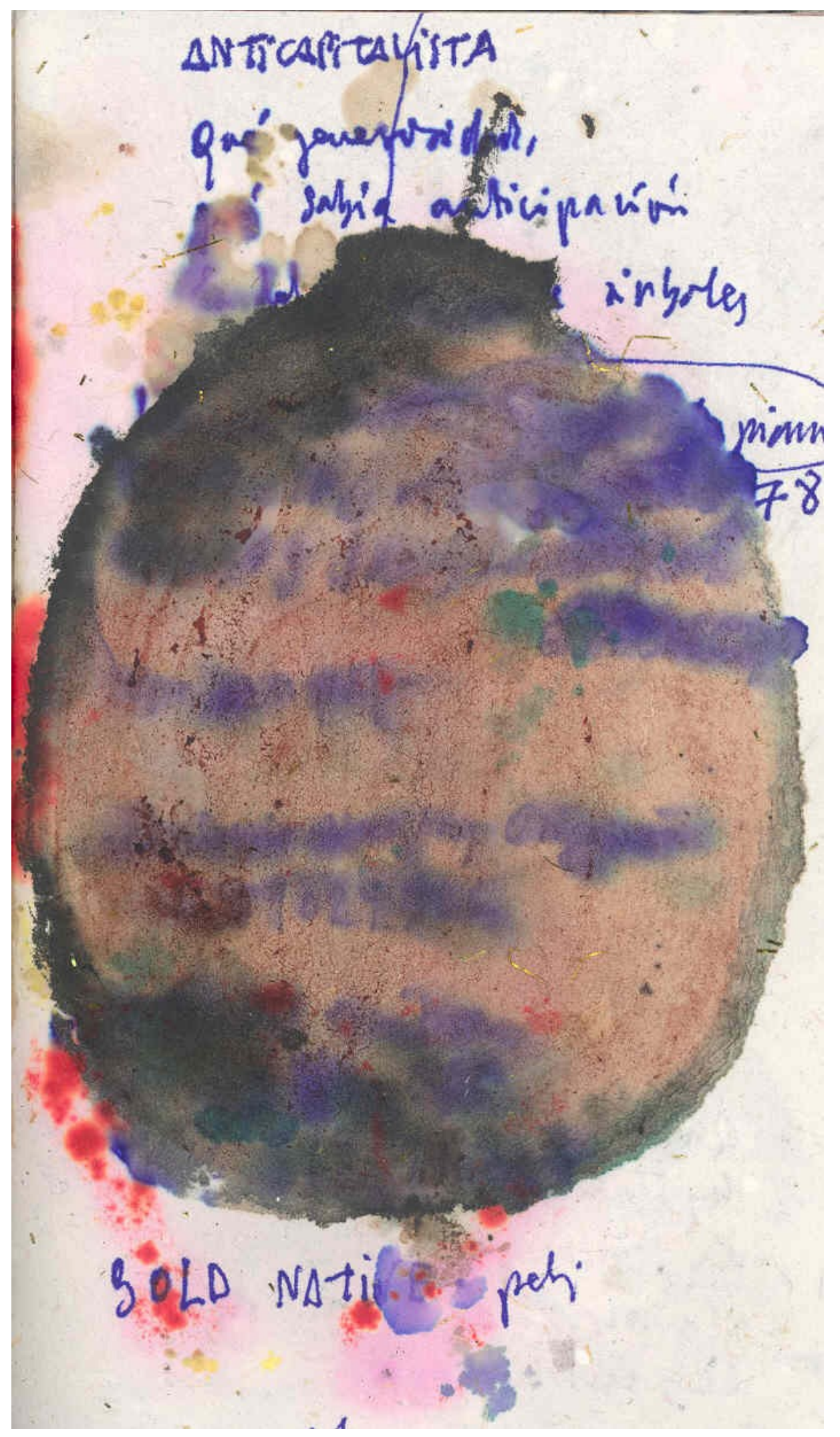

Antonio Orihuela, Anticapitalista. 
El silencio de las palabras borradas que evocan la censura protagoniza "Anticapitalista" (Díaz Rosales, 2014b: 342), de Antonio Orihuela (Moguer - Huelva, 1965). Mediante la ilegibilidad debida a la mancha, como si una gota hubiera hecho que la tinta desvaneciera, la obra insinúa que hay un discurso negado en nuestro sistema social, algo que, aunque se escriba, no es percibido con la merecida atención. Los conocimientos que proceden del pasado y que nos llevarían a juzgar la situación desde un punto de vista más sólido y racional parecen haber caído en el olvido y, sin embargo, están ahí, aunque es un mensaje velado: desde el margen, siempre habrá alguien avisando de lo que ocurre, por ejemplo a través de la poesía visual. El fantasma del desengaño queda patente en las pocas palabras que se pueden leer: el título, la desilusión del fragmento "qué generosidad, / qué sabia anticipación", el "78" que remite probablemente al año de la Constitución española, evocando la promesa de democracia luego incumplida, y la expresión inglesa "sold natuives", donde los nativos vendidos aluden a la esclavitud.

La pérdida de las posibilidades comunicativas y del sentido, en este caso debida al libro cerrado y mutilado, protagoniza la obra de Fernando Millán (Jaén, 1944) publicada por primera vez como "Opresión capital" (Bianchi, 2014: 14); al saber que se reproduciría en este artículo, el autor pidió que se modificara el título, indicando el que hubiera tenido que aparecer desde el primer momento: "La opresión de El capital". En la primera versión, la relación entre el contenido y el título que jugaba con la homofonía -sugiriendo que el capital entendido como dinero es la "opresión capital" de nuestra sociedad- generaba inevitablemente un guiño en el espectador; pese a que el cambio anula este efecto, la interpretación sigue siendo la misma. Los tres tomos del conocido tratado de economía política de Carlos Marx, símbolo cargado de historia, emociones, valores e ideología, se presentan, de acuerdo con la técnica del antilibro, en una circunstancia sorprendente que

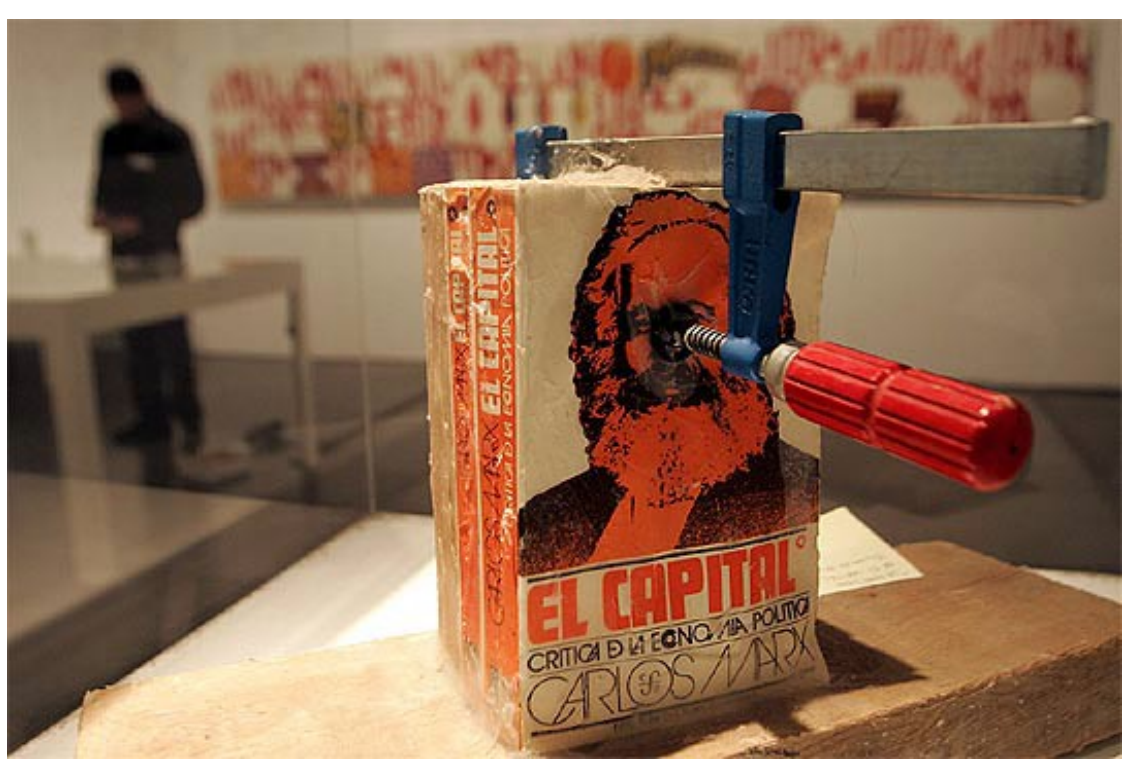

Fernando Millán. La opresión de El capital

\footnotetext{
${ }^{6}$ En respuesta a mi mensaje del 23 de octubre 2014, en el que le pedía permiso para reproducir aquí la obra, el autor manifestó la voluntad de corregir el título en su correo electrónico del 24 de octubre de 2014: "Tu petición (que concedo gustosamente) me permite corregir la errata que había en el nombre de este poema. Su título completo es "La opresión de El capital". Es muy importante que se pueda leer el título completo para entender la intención del autor, que busca remarcar la opresión (o persecución) que los neoliberales llevan más de un siglo practicando con El capital de Carlos Marx." El error se debe a que, cuando Fernando Millán lo mandó para la publicación en Duende (Bianchi, 2014: 14), en el nombre del archivo figuraba la forma abreviada "Opresión capital".
} 
rompe las expectativas, obligando al público a que reflexione: los volúmenes están encerrados en una mordaza cuyo hierro los traspasa de parte a parte. No sólo el utensilio no permite abrirlos, sino que, además, cada página ha perdido un fragmento por el agujero: el comunismo es un paréntesis cerrado de la historia, una temporada acabada que ha dejado la plaza al consumismo y de la que inevitablemente se ha perdido algo. Seguramente no queremos ver o nos hemos olvidado de las consecuencias negativas de la acumulación del capital, en términos de explotación de la masa (el proletariado de Marx) por parte de los pocos dueños de la riqueza y del poder (la burguesía), puesto que aceptamos sin reaccionar la misma sumisión de la gran mayoría de los seres humanos a las leyes del mercado.

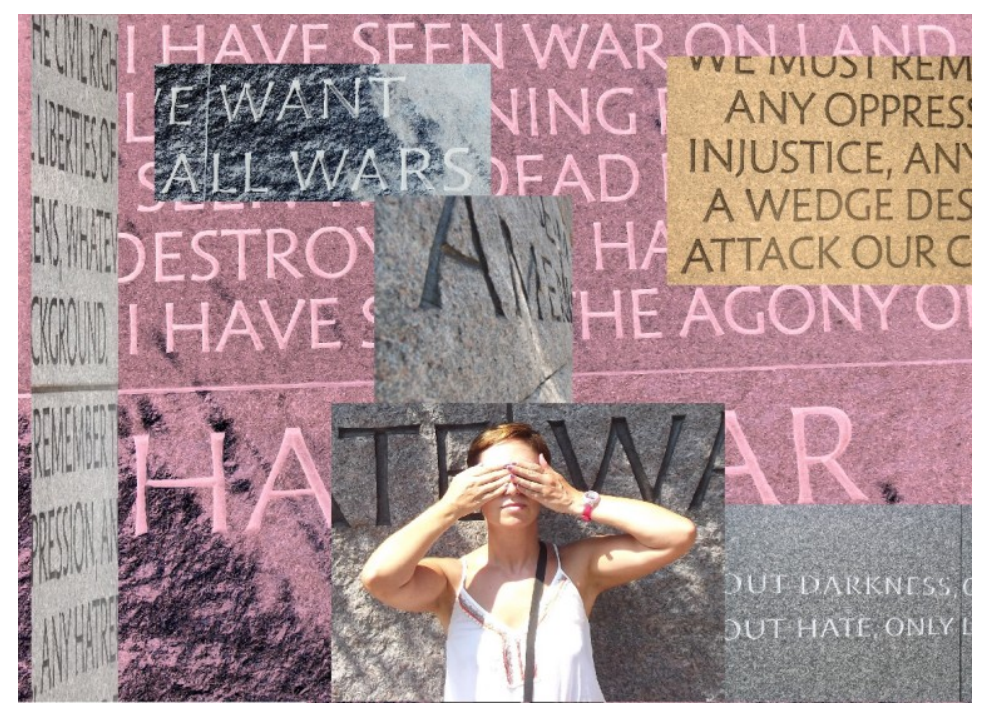

Carmen Peralto, Acción por la paz (Washington DC 2012)

Otro grupo de obras invita a la reflexión sobre el desorden, el deseo frustrado, la confusión y el desconcierto que rigen nuestras vidas sin que nos demos cuenta, transformando al ser humano en un individuo alienado y sin esperanzas en el futuro. En este conjunto y manteniendo el juego de las palabras borradas -obtenido aquí con la técnica del collage donde los textos superpuestos esconden el del fondo-, "Acción por la paz (Washington DC 2012)" (Díaz Rosales, 2014b: 371) de Carmen Peralto (Málaga, 1967) denuncia otro aspecto negativo de nuestra época: la guerra, que, aunque indirectamente, también remite a la falta de diálogo entre los hombres. Los pensamientos de la mujer con los ojos tapados de la imagen central toman forma en las palabras de las citas de Franklin D. Roosevelt ${ }^{7}$, que bien podrían describir lo que ella siente o ha visto y no quiere volver a ver: "hate war" y, sobre el fondo rosa, "I have seen war on land", "dead" "destroy" "agony". El

\footnotetext{
${ }^{7}$ Los fragmentos de las citas de Franklin D. Roosevelt que se ven en el poema visual son detalles de fotos sacadas en el Franklin Delano Roosevelt Memorial, en Washington, y proceden en su mayoría de los siguientes enunciados: "I have seen war. I have seen war on land and sea. I have seen blood running from the wounded... I have seen the dead in the mud. I have seen cities destroyed... I have seen children starving. I have seen the agony of mothers and wives. I hate war" (14 agosto 1936); "More than an end to war, we want an end to the beginnings of all wars" (discurso preparado para el 13 abril 1945).
} 


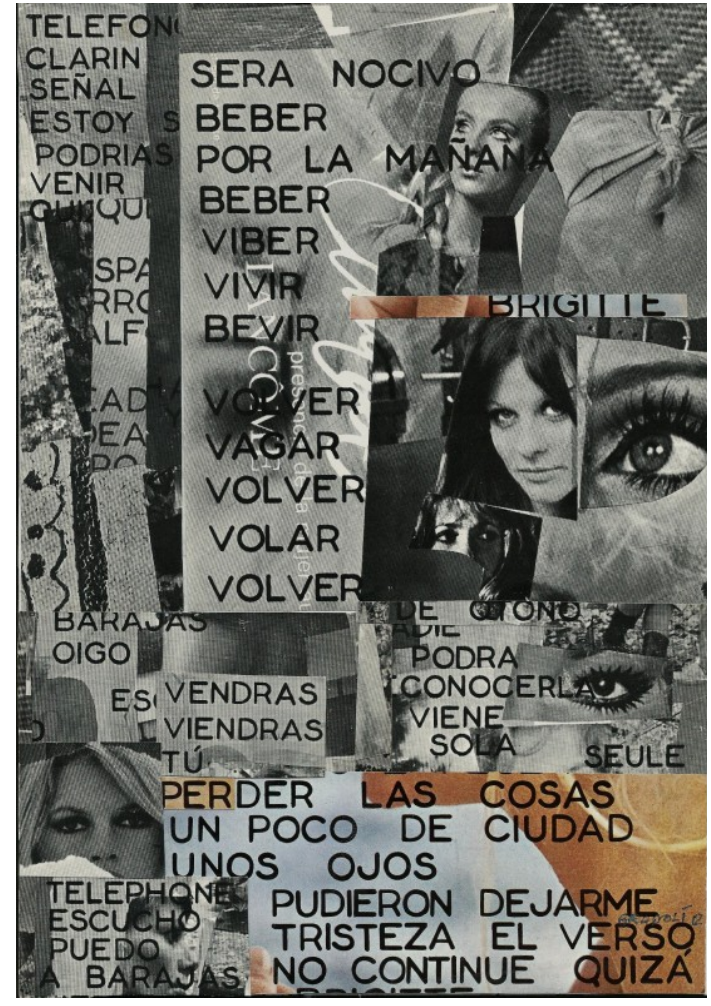

Alfonso López Gradoli, Collage

poder y el dinero anulan cualquier intento de tolerancia, cancelan los derechos humanos cuando no la vida misma, y nos obligan a un espectáculo macabro que fingimos no ver o que ya no vemos por estar tan acostumbrados a él.

Por otro lado, en "Collage" (Bianchi, 2014: 13), donde tanto la frase como la imagen se descomponen, Alfonso López Gradoli (Valencia, 1943) enjuicia la nombrada "tristeza" del hombre por su soledad, evocada mediante las palabras y las miradas -tema que trataremos en breve- de la mujer inalcanzable, cuyo emblema es sin duda Brigitte Bardot, presente tanto en las fotos como en la transcripción de su nombre. Ella es igualmente sola por ser el complemento directo de la oración "nadie / podrá / conocerla" y sujeto de la siguiente: "viene / sola"; su imagen, que procede del cine y de los medios de comunicación de masas, se vuelve objeto prohibido del deseo sobre el que se basa la sociedad de consumo. El ser humano frustrado, alienado y perdido corre el riesgo de buscar un alivio de la pena en el alcohol: "será nocivo / beber / por la mañana", cuyo verbo da origen a una lista de otros surgidos por paronomasia. Lo mismo ocurre con "volver", repetido tres veces, como en la ebriedad o en la neurosis del sueño irrealizable de volver a encontrar el tú -explicitado en la segunda persona singular del condicional "podrías / venir", contrapuesto a la primera del "estoy"-, y alternado con "vagar" y "volar", que remarcan la ausencia de un destino concreto y de puntos de referencia, ya evidente en las expresiones "perder las cosas / un poco de ciudad" y "unos ojos / pudieron dejarme".

Gustavo Vega (Villaverde - León, 1948), desde su "Ángulo muerto" (Díaz Rosales, 2014b: 75), delata el caos generalizado que rodea al ser humano en un poema tradicional que se vuelve visual por la disposición que forma un círculo y la técnica tipográfica: el negro, el blanco y el gris remiten a la ausencia de color desde el primer momento, y las saetas

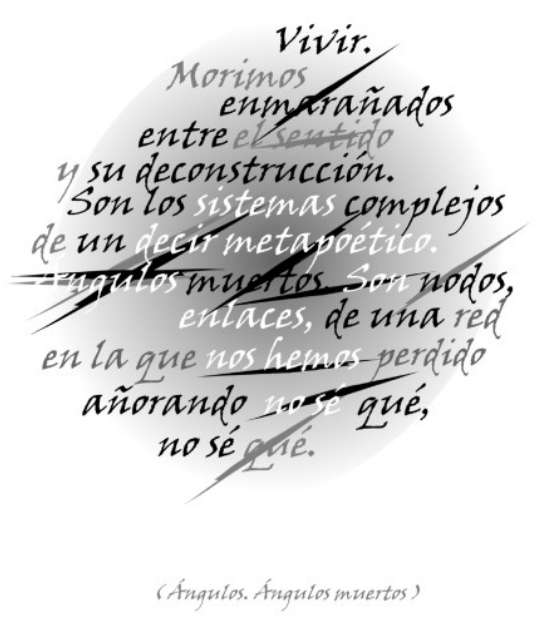

Gustavo Vega, Ángulo muerto 
de las mismas tonalidades caen sobre las palabras, hiriéndolas como ellas hieren al lector. Los versos advierten que vivimos en la mentira y el engaño: "Morimos enmarañados entre el sentido y su deconstrucción". Estamos en un "sistema complejo", perdidos en "una red" que remite a la comunidad virtual, donde la ilusión de no estar solos no soluciona la soledad real que nos oprime, y la falsa libertad según la que quienquiera pude decir cualquier cosa esconde que nada de lo que se diga tiene verdadera importancia. Sin embargo, la sensación de nostalgia nos manda señales de que algo no funciona: vivimos "añorando no sé qué, / no sé qué", donde la respuesta implícita incluiría la libertad, la sinceridad, la inteligibilidad, la simplicidad y la humanidad.

A su vez, Rafael de Cózar (Tetuán, 1951) aclara una de las posibles pérdida en su "Ojos" (Díaz Rosales, 2014b: 128), donde, a pesar de la disposición de los versos y del protagonismo de la imagen, se puede leer el poema escrito de forma tradicional. En una perfecta sinergia de los elementos visuales y verbales, la primera impresión que recibe el espectador es positiva: los ojos tienen al principio del texto "hambre de vida", la mirada central se impone, atrayendo por su intensidad y su inocencia, la predominancia del azul y del lila produce una sensación cromática muy agradable y relajante. Avanzando en la observación, se nota el perfil del rostro de un hombre, con una expresión poco serena; al mismo tiempo, procediendo en la lectura, los ojos tienen "hambre de tiempo" y dejan aflorar la época feliz de la niñez. Sólo al final percibimos la negatividad de la "infancia / que perdimos", que, asociada al perfil masculino, evoca la ausencia de la ingenuidad. Por último, divisamos el dibujo del ojo vacío, sin pupila y sin iris, como si el hombre, además, hubiera perdido la visión. El ojo aparece constantemente no sólo en la poesía visual, sino también en la vanguardia histórica, sobre todo el

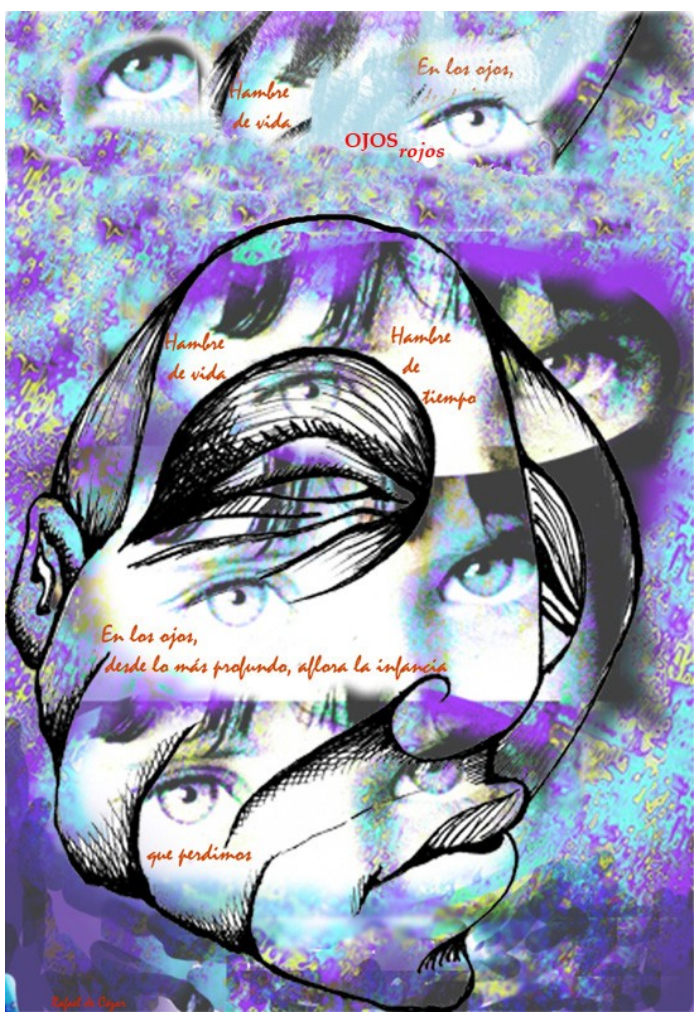

Rafael de Cózar, Ojos película de Buñuel Le chien andalou (1929)-, avisando al espectador sobre la necesidad de observar desde una perspectiva no convencional. El resultado final es la anulación de la emoción inicial positiva, que produce en el lector-observador la misma sensación de pérdida que protagoniza la obra, obligándolo a pensar en todo lo que él mismo ha dejado en el camino de la vida.

\section{Conclusiones}

Hoy en día muchos estudiosos niegan la actitud crítica de la reciente poesía visual. Entre ellos y en desacuerdo con algunas de las obras que él mismo crea, Antonio Orihuela (2014: 72-73) considera que ésta no se puede inscribir dentro de la vanguardia y que sus 
postulados tienen más que ver con la moda basada en la alteración de los códigos que con el compromiso ético de la voluntad de transformación de la realidad; en sus palabras, los poetas visuales:

se podrían agrupar dentro de aquellas coordenadas que definió Pignatari como propias no ya de un movimiento de vanguardia sino como un efecto típico de la resaca de las vanguardias; o dicho de otro modo, en estos últimos cincuenta años lo que hemos hecho no ha sido más que asistir, una y otra vez, a su folclorización, a la reproducción manierista de sus formulaciones. [...] estamos ante una experimentación que ha borrado de sí toda huella de utopía a la vez que señala la senda de su fetichización mercantilista.

En efecto, desgraciadamente, el vanguardista se ha transmutado en artista; hace tiempo que dejó de querer transformar el mundo, le basta con apenas participar en él, de ahí la dificultad para encontrar nuevos cauces expresivos dentro de una experimentación visual que celebra el mundo en que vivimos y que es incapaz de desplegar una percepción diferente de él (Orihuela, 2013: 55).

Orihuela (2013: 56-57) concluye entonces que:

La poesía visual que se planteó por sus iniciales operadores como una forma de activismo se agotó en la mera actividad de su propia producción estética, sin capacidad de intervención social, y en las sangrantes luchas intestinas que se vivieron en la construcción de liderazgos entre sus integrantes.

El crítico remarca luego la falta de correspondencia entre el propósito teórico, radical, trasgresor y utopista, y las prácticas que no logran modificar la realidad ni escaparse a la semantización de la imagen globalizada "como producto socialmente significante", volviéndose ellas mismas "fuente de alienación capitalista" (Orihuela, 2013: 59).

Asimismo, Blanca Millán Domínguez (2014: 126 y 128) reconoce en la producción de los últimos años un alejamiento de la rebelión vanguardista, del radicalismo y de la actitud crítica de la primera época de la poesía visual, es decir, un abandono de las cuestiones éticas o políticas que son ausentes en las nuevas generaciones. No obstante, ella misma admite que "hay autores hoy en día que continúan trabajando contra los modelos establecidos" (Millán Domínguez, 2014: 126), entre los que cita a Bartolomé Ferrando, Antonio Gómez, Fernando Millán y Francisco Peralto. Más adelante hace hincapié en que "el sustrato revolucionario y trasgresor inicial de la poesía experimental ha ido diluyéndose a medida que su lenguaje ha sido asumido por los medios de comunicación y la publicidad" (Millán Domínguez, 2014: 128), influenciados ellos mismos por la poesía visual y la performance, que son "las grandes aportaciones del siglo XX" (Millán Domínguez, 2014: 128); según ella, el riesgo es que las nuevas formas artísticas se conviertan en un medio más de propaganda y difusión de la cultura del consumo. Sin embargo, la autora cierra su estudio con una afirmación alentadora, que parece confirmar nuestra tesis (Millán Domínguez, 2014: 129):

Afortunadamente, [...], una serie de poetas visuales y experimentales continúan a día de hoy trabajando al margen del mercado del arte, manteniendo así el 
espíritu inicial de transgresión y experimentalismo y contradiciendo las teorías que afirman que el de la poesía experimental es un ciclo terminado.

Pese a los límite impuestos por el espacio, que han reducido el caudal de nuestros ejemplos, creo que hemos demostrado con creces que el remarcado alejamiento de la disidencia no se corresponde con la realidad: afortunadamente, los poetas visuales de calidad, que no se olvidan de ninguna de las dos vertientes de este género plástico-literario, siguen afirmando su disconformidad, en la medida en que denuncian la alienación, la dependencia del dinero, la incomunicación y la soledad a la que el presente sistema social, ininteligible, nos obliga. Proponiendo su heterodoxia desde el mismo lenguaje postmoderno que critican -es decir, usando la misma predominancia de la imagen-, nos obligan a reflexionar sobre el consumismo, el caos, la superficialidad y la deshumanización de los que somos víctimas, lo mismo que sobre el sentido de la misma imagen en nuestra cultura.

En otras palabras, asumiendo las teorías de Marshall McLuhan acerca de nuestra sociedad como resultado de la revolución tecnológica en la comunicación de masas y del imperio de la representación, los creadores que hemos citado proponen un arte que pretende erradicar la cultura capitalista para instaurar un nuevo sistema social, o por lo menos afirmar que una realidad distinta es posible. Los artistas modifican así la percepción del mundo de quienes cumplen con la tarea activa del lector, que requiere que éste no se limite a observar de forma pasiva, sino que le pide que construya significado, complementando la obra con sus claves interpretativas y sus cavilaciones ${ }^{8}$. De esta manera, los autores se acercan no sólo a formas secundarias del compromiso, sino a su misma y más atávica definición: la de Jean-Paul Sastre, quien en su Qu'est que c'est la litterature de 1948 afirma que revelar es cambiar, y que se escribe -aunque en nuestro caso sería preferible el verbo crear- para que nadie pueda ignorar la realidad del mundo.

Contra el falso poder del dinero, de la imagen publicitaria y del consumismo, parecen sugerir los poetas visuales desde los años setenta hasta hoy, no hay mejor arma que la del conocimiento, que hace que el pueblo tome conciencia de lo que está viviendo. Ha cambiado el tirano y, con él, las formas de expresión para describirlo, pero la solución es la misma que los intelectuales han venido proponiendo a lo largo de los siglos, desde el compromiso ético con las distintas realidades con las que han tenido y tienen que enfrentarse.

\footnotetext{
${ }^{8}$ Como apunta Juan Carlos Serrato: "para que se produzca el funcionamiento poético de estas prácticas estéticas [...] es necesaria la presencia de un discurso hermenéutico que haga posible la comprensión lectora y la consecuente estimación literaria. [...] Fenómenos observables en el poema visual, [...] resultan incomprensibles para el destinatario si este no efectúa previamente una ampliación de sus códigos de lectura. Tal ampliación se obtiene saltando del texto presentado como artístico al extratexto de las convenciones estéticas, por una parte $\mathrm{y}$, por otra, a ese discurso metapoético y hermenéutico fuertemente perlocutivo producido por los propios autores del experimentalismo literario español, cuya finalidad última hemos cifrado precisamente en la formación de la competencia decodificadora de los posibles lectores". (Fernández Serrato, 2014: 148).
} 


\section{Bibliografía citada}

Adorno, Theodor (2003). Obra completa. Madrid: Akal.

Asamblea General de las Naciones Unidas (1948). Declaración Universal de Derechos Humanos. Paris.

Austin, John L. (1962). How to do Things with Words. Oxford: Oxford University Press.

Bajtín, Mijaíl (1986). Problemas de la poética de Dostoievski (1929). México D. F.: Fondo de Cultura Económica.

Barthes, Roland (1953). Le degré zéro de l'écriture. Paris: Seuil.

Baudrillard, Jean (1981). Simulacres et Simulation. Paris: Galilée.

Bianchi, Marina (ed.) (junio 2014). Duende. Suplemento virtual de Quaderni Ibero Americani 9.

Bianchi, Marina (2008). "Los artículos 'a lo femenino' de María de la Concepción Gimeno de Flaquer". Bernard, Margherita; Chierichetti, Luisa; González de Sande, Mercedes; Rota, Ivana (eds.). Mujeres de papel / Papel de mujeres, actas del Seminario Internacional, 12 de diciembre de 2007. Bergamo: University Press Sestante Edizioni: 21-49.

Canals, Xavier (1999). "No caduca. Una historia de la poesía visual catalana”, introducción a Poesía visual catalana [catálogo]. Barcelona: Centre d'art Santa Mónica.

Cózar, Rafael de. "Apuntes para una prehistoria de la vanguardia". Tintas [Experimental, ed. de Raúl Díaz Rosales] n. extraordinario (2014): t. I, 3-30.

Cózar, Rafael de. "La experimentación con la palabra y su contexto histórico". La manzana poética 34-35 (septiembre-noviembre 2013): 7-13.

Cózar, Rafael de. "Carlos Edmundo de Ory: el postismo y la vanguardia". Insula 789 (septiembre 2012): 7-9.

Cózar, Rafael de (1991). Poesía e imagen. Sevilla: El Carro de la Nieve.

Debord, Guy (1967). La société du spectacle. Paris: Buchet-Chastel.

Díaz Rosales, Raúl (ed.) (2014a). Tintas. Experimentaln. extraordinario, t. I Estudios.

Díaz Rosales, Raúl (ed.) (2014b). Tintas. Experimental n. extraordinario, t. II Creaciones.

Eco, Umberto (1979). Lector in fabula. Milano: Bompiani.

Eco, Umberto (1990). I limiti dell'interpretazione. Milano: Bompiani.

Fernández Serrato, Juan Carlos. "Textualidad y poesía experimental en la generación del 70". Tintas [Experimental, ed. de Raúl Díaz Rosales] n. extraordinario (2014): t. I, 141-150.

Grice, Paul (1975). "Logic and Conversation". Cole, Peter y Morgan, Jerry L. (eds.). Syntax and Semantics 3: Speech Acts. New York: Academic Press: 41-58.

Jameson, Fredric (1991). Postmodernism, or, The Cultural Logic of Late Capitalism. Durham: Duke University Press.

Kristeva, Julia (1981). Semiótica 2 (1969). Madrid: Fundamentos.

Lotman, Jurij (1978). La estructura del texto artístico (1970). Madrid: Istmo. 
McLuhan, Marshall (1968). War and Peace in the Global Village. New York: Bantam.

McLuhan, Marshall (1964). Understanding Media: The Extensions of Man. New York: McGraw-Hill.

Millán Domínguez, Blanca. "Visualidad y experimentación en la poesía de neovanguardia española". Tintas [Experimental, ed. de Raúl Díaz Rosales] n. extraordinario (2014): t. I, 113-140.

Millán, Fernando y García Sánchez, Jesús (eds.) (1975). La escritura en libertad. Antología de la poesía experimental. Madrid: Alianza.

Orihuela, Antonio. "Ciclo cerrado: la poesía experimental en España (1964-2004)". Tintas [Experimental, ed. de Raúl Díaz Rosales] n. extraordinario (2014): t. I, 57-111.

Orihuela, Antonio. "Antivanguardia y desencanto en la poesía experimental española". La manzana poética 34-35 (septiembre-noviembre 2013): 55-60.

Ramírez, Juan Antonio (1997). Medios de masas e historia del arte. Madrid: Cátedra.

Real Academia Española. Diccionario de la lengua española.

Sartre, Jean-Paul (1948). Qu'est ce-que la littérature. Paris: Gallimard.

Searle, John (1969). Speech Acts. Cambridge: Cambridge University Press.

Sperber, Dan y Wilson, Deidre (1986). Relevance: Communication and Cognition. Oxford: Blackwell.

Urrutia, Jorge. "Poética con man(ual)". La alegría de los naufragios. Revista de poesía 1-2 (1999): 135-136.

Vega Mansilla, Gustavo. "Poéticas tridimensionales (España 1970-1995)". Tintas [Experimental, ed. de Raúl Díaz Rosales] n. extraordinario (2014): t. I, 151-166.

Vega, Gustavo. "Poéticas de creación visual". Alga. Revista de literatura 54 (otoño 2005): s. p.

Williams, Raymond (1997). Marxismo y literatura. Barcelona: Península. 